\title{
A Full-Bridge Bidirectional DC-DC Converter with Fuzzy Logic Voltage Control for Battery Energy Storage System
}

\author{
Eka Prasetyono, Epyk Sunarno, Muchamad Chaninul Fuad, \\ Dimas Okky Anggriawan, Novie Ayub Windarko \\ Department of Electrical Engineering \\ Politeknik Elektronika Negeri Surabaya \\ Kampus PENS Jalan Raya ITS, Sukolilo, Surabaya 60111 Indonesia \\ Email: eka@pens.ac.id, epyk@pens.ac.id, chaninul@staff.pens.ac.id, \\ dimas@pens.ac.id,ayub@pens.ac.id
}

\begin{abstract}
Renewable energy sources require an energy storage system because its are fluctuating and electricity producing at certain times, even sometimes not in accordance with the needs of the load. To maintain continuity of electricity, smart battery energy storage system is needed. Therefore, this paper of a full-bridge bidirectional DC-DC Converter (FB-BDC) with Fuzzy Logic Control (FLC) is designed and implemented for battery energy storage application. The FLC has error and delta error of voltage level as input and duty cycle of FBBDC as output. The FB-BDC is controlled by a microcontroller ARM Cortex-M4F STM32F407VG for voltage mode control. The FB-BDC topology is selected becuase battery storage system needed isolated and need high voltage ratio both for step-up and step-down. The main purpose of FB-BDC to perform bidirectional energy transfer both of DC-Bus and battery. Moreover, FB-BDC controls the DC-Bus voltage according to referenced value. The power flow and voltage on DC-Bus is controlled by FLC with voltage mode control. The experiment result shows the ability of FLC voltage mode control to control FB-BDC on regulate charging voltage with an error $1 \%$ and sharing voltage $1.5 \%$ form referenced value.
\end{abstract}

Keywords: full-bridge bidirectional DC-DC Converter, Fuzzy Logic Controller, Battery Energy Storage System.

\section{INTRODUCTION}

The growth of electrical energy consumption increase appropriate with the increasing of population and demands for a higher standard of living [1]. To fulfil demand of electricity, some countries use renewable energy sources including Indonesia [2-3]. Generally, renewable energy sources are strongly influenced by the environment condition and there are many deficiencies in its implementation. The renewable energy cannot be found in 
every place, only certain places that have renewable energy sources and renewable energy produced sometimes not in accordance with the demand of the load [1]. For example, Photovoltaic power generation is one of renewable energy source, which it can only be used during the day. Moreover, wind turbine only can be used for certain wind speed.

One of the efforts developed by researchers of renewable energy in efforts to maintain continuity is developing of energy storage systems with energy storage technology, which it can store the electricity and can be used as quickly as possible. The battery energy storage technology able to help improve the reliability of the electric power system due to the demand for electrical energy that changes throughout the day. Therefore, energy storage technology is used as a method to store energy when energy demand is low and will be used to help supply energy when energy demand is high. Figure 1, illustrated the way to keep continuity of electricity using battery energy storage system, when energy produced higher than load demand, the surplus energy will be stored in battery, but when the load demand energy is higer than produced energy, the battery will be discharge to meet load demand.

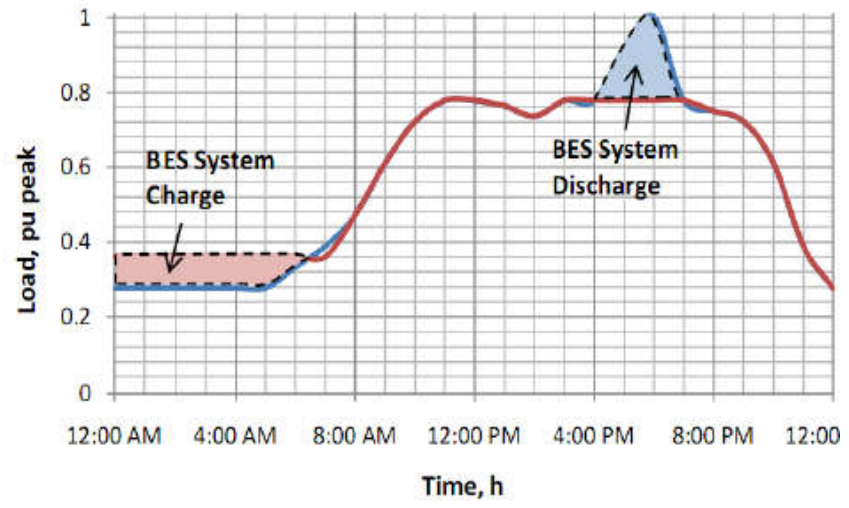

Figure 1. Battery Energy storage system (BES) to help increase the continuity of electrical energy. [1].

One of the easy ways to control power flows on battery energy storage system is equipped with a bidirectional DC-DC converter. A Bidirectional DCDC converter is a power converter that can work in two directions, charging mode to store energy into the battery and discharging mode to deliver electrical energy from the battery to the load [4-7]. Bidirectional DC-DC converter topology can be classified into two categories: non-isolated and isolated topology [8-9]. In this paper the topology discussed is isolated bidirectional DC-DC converter using isolated bidirectional Fullbridge DC-DC converter. The advantages of this converter are isolated for isolation security where the input circuit and output circuit are sparately not connected, also used at high voltage and easily implemented hardware [10-14]. Figure 2. illustrates position of bidirectional DC-DC Converter to enable bidirectional power flows between DC Bus and battery or another energy storage system. 


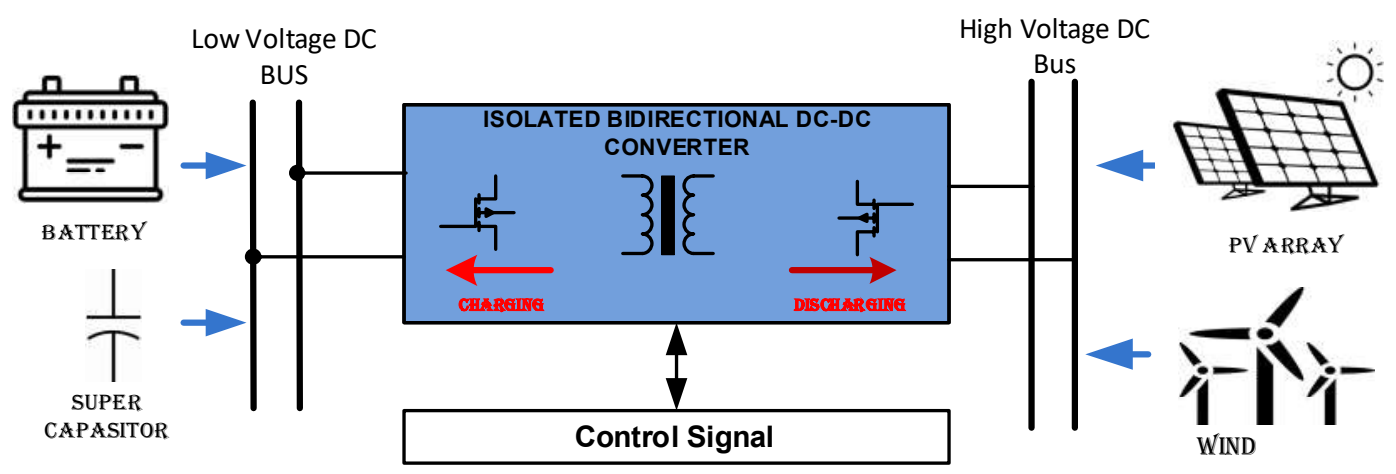

Figure 2. Bidirectional DC-DC Converter position on energy storage systems.

According to the principle of a bidirectional DC-DC converter, power flow can be transferred both from the battery to the high voltage DC Bus or from the Low voltage DC Bus to the battery, then operation modes of converter are varied based on unpredictable power flow determined by energy sources and load demand. To enable these operation modes, an automatic and fast response controller are needed to control power flow. In this paper fuzzy logic controller is selected and implemented in the ARM Cortex M4 32bit STM32F407 Microcontroller to control power flow of bidirectional DC-DC converter.

\section{RELATED WORKS}

The DC-DC converter is a device used to transfer DC power flow with vary of voltages. DC-DC converter can be used for adding or reducing of voltage. the DC-DC converter clasified on two categories, unidirectional and bidirectional. The unidirectional DC-DC converter is a device used to convert voltage level and control power flow on direction determined. Moreover, a bidirectional DC-DC coverter is a device used both to convert voltage level and control power flow on two directions [8-9]. There are many topology of bidirectional DC-DC coverter was developed by reseacher, one of the famous type is full-bridge bidirectional DC-DC converter (FB-BDC). The FB-BDC topology is recomended for battery storage system because it has high voltage ratio both for step-up and step-down, easy to control power flow, high efficiency and anable to transfer high power [7-11].

The FB-BDC requires very simple electronic components, namely in the form of MOSFETs as component switching, Fast Recovery diode, high frequency transformers as step-up and step-down in voltage and also work as isolated input power to output power, inductors and capacitors for filter to reduce ripple current. Figure 3. ilustrated circuit of FB-BDC. 




Figure 3. The circuit of FB-BDC

The FB-BDC have two work operating modes, namely charging mode for step-down DC voltage and sharing mode to step-up DC voltage.

\subsection{FB-BDC Charging Mode.}

In the charging mode, FB-BDC operated work to reduce the voltage, where the output voltage will be smaller than the input voltage. The relationship between the output voltage and the input voltage for charging mode can be formulated in equation 1 , where Vout is output voltage, Vin is input voltage, Ns is the number of scondary winding, $\mathrm{Np}$ is the number of primary winding and $\mathrm{D}$ is duty cycle.

$$
\mathrm{V}_{\text {out }}=2 \frac{\mathrm{N}_{\mathrm{s}}}{\mathrm{N}_{\mathrm{p}}} \mathrm{V}_{\text {in }} \mathrm{D}
$$

In the charging mode, the input power is from DC BUS, then the voltage is reduced and power lows for charging the battery. In this charging mode the power flows through switch S5-S8 [8-11]. The switch work alternately, if the S5 and S8 are active, the S6 and S7 are not active. Whereas S1-S4 is not switched or open condition, internal diode is used as a rectifier. The switching pattern can be seen on Figure 4 and the power flow on circuit for charging mode as shown in Figure 5, the red color mean power flow through the line.

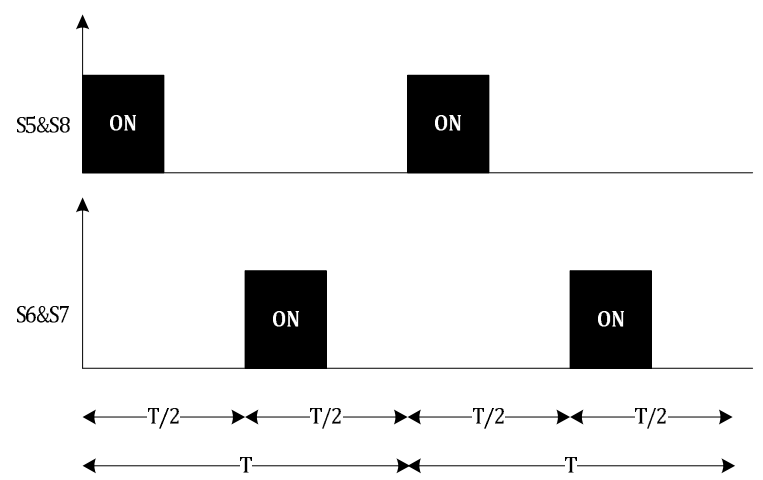

Figure 4. Switching pattern of FB-BDC for charging mode operation 

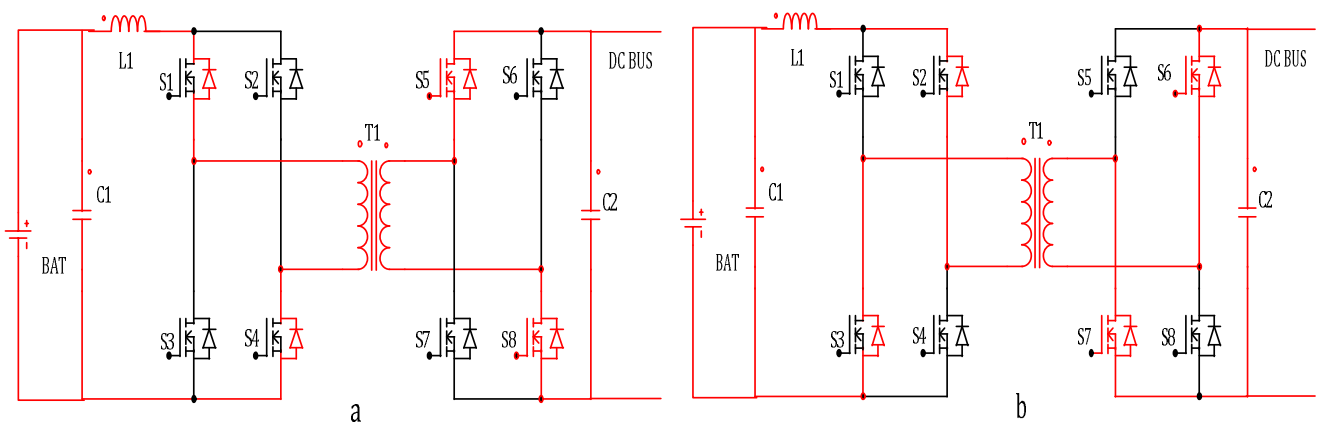

Figure 5. The sequence and power flow of FB-BDC for charging modes (a) phase 0-180, (b) phase 180-360.

\subsection{FB-BDC Sharing Mode.}

In the sharing mode FB_BDC operated to work to increase the voltage, where the output voltage will be greater than the input voltage. The relationship between the output voltage and the input voltage for the sharing mode can be formulated in equation 2, where Vo is output voltage, Vin is input voltage, $\mathrm{N} 2$ is the number of scondary winding, $\mathrm{N} 1$ is the number of primary winding and $\mathrm{D}$ is duty cycle.

$$
\mathrm{V}_{\mathrm{o}}=\frac{\mathrm{N}_{2}}{\mathrm{~N}_{1}} \frac{1}{2(1-\mathrm{D})} \mathrm{xV}_{\mathrm{in}}
$$

In the charging mode, the input power comes from the battery. The voltage is then reduced and power flows to supply the load. In the charging modethe power flows through S1 - S4 [8-11]. The switch work alternately, if S1 and S4 are active, the S2 and S3 are not active. Whereas S5-S8 is not switched or open condition, internal diode is used as a rectifier. The switching pattern can be seen on Figure 6 and the power flow on circuit for sharing mode as shown in Figure 7, the red color mean power flow through the line.

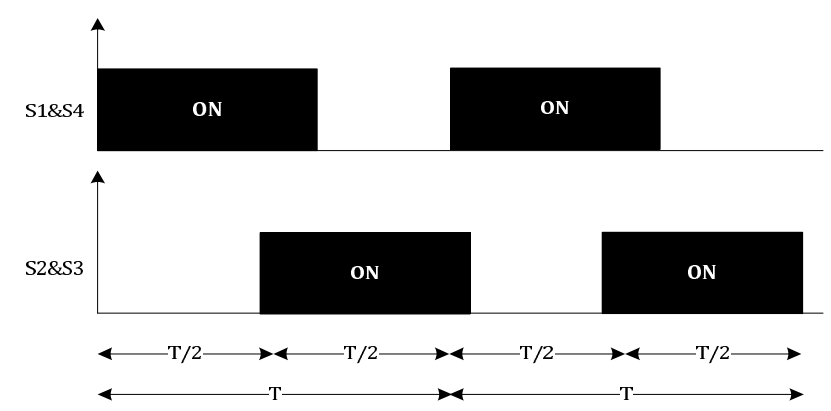

Figure 6. Switching pattern of FB-BDC for sharing mode operation 


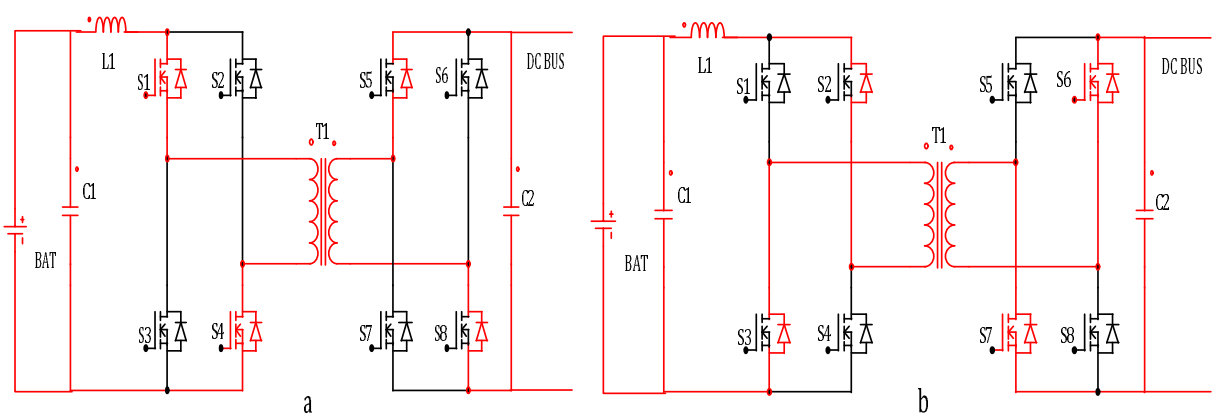

Figure 7. The sequence and power flow of FB-BDC for sharing modes (a) phase 0180 , (b) phase 180-360.

The magnitude power flows of FB-DBC both for charging and sharing mode operation are determined by PWM. To perform precisely power flow on fluctuated condition precise PWM is needed, the way to get precise PWM researcher susgedted by applying intelligent controller. The Fuzzy Logic Controller is the one of the recomended controller by researcher [15-18], because it simple, can be done through computer simulation and can also be embedded in a microcontroller. The fuzzy logic controller for DC-DC converter application does not require too much computational process.

\section{ORIGINALITY}

As mentioned in the introduction, this paper discusses about the bidirectinal DC-DC converter for energy storage system, especially using FullBridge DC-DC converter controlled with fuzzy logic controller. In this paper emphasizing of implementation in hardware not only by software simulation. The Experimental used 311 volts of DC Bus and Battery 72 volts, and the fuzzy logic controller as controller is implemented in STM32F407 microcontroller to automatically control the power flow both for charging and sharing bettwen DC Bus and battery according to load requirements. The contribution of this paper is generating real time control with fuzzy logic controller to control power flow of FB-BDC on energy storage system.

\section{SYSTEM DESIGN}

The block diagram of FB-BDC for battery energy storage systems with fuzzy logic controller can be seen in Figure 8. The FB-BDC design for the main DC Bus is assumed to be from renewable source energy with nominal voltage 311 Volt DC and its can be varying from 300 Volts to 340 Volts, the FB-BDC completed with isolated gate drivers to enable control from microcontroller, and also provided with isolated voltage sensors and monitoring devices. The input of fuzzy logic controller comes from the the voltage sensor readings by ADC (analog to digital converter) of microcontroller. This reading value then convert to the membership function of error and delta error, after that the degree of membership of error and delta error evaluate with rule base and then processed by defuzzyfication to determine PWM duty cycle. 


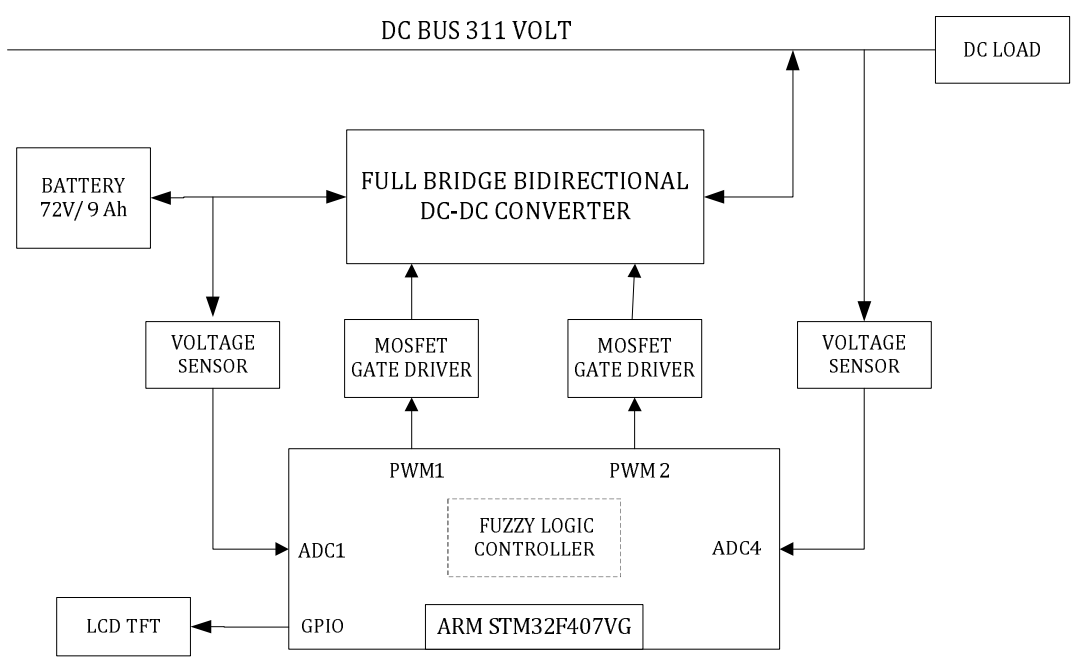

Figure 8. Block diagram of proposed FB-BDC for battery energy storage systems.

The proposed FB-BDC has three operating modes namely charging mode, sharing mode and stanby mode. The operating mode of this converter is selected automatically with principle operating procedure described in Figure 9. The charging mode is activated when the voltage on the DC BUS reaches a voltage greater than or equal to $320 \mathrm{~V}$. This charging mode will be used to store energy by charging the battery of $72 \mathrm{~V} 9 \mathrm{Ah}$. This charging mode will turn off when the voltage on DC Bus experiences a decrease in to $315 \mathrm{~V}$ or specified set point. In this state, it is defined as a low load demand state on DC Bus.

The FB-BDC sharing mode is actived when the voltage on DC Bus experiences a decrease below $311 \mathrm{~V}$ or the set point of network voltage system on the DC Bus black out. This sharing mode will turn off when the voltage on DC Bus experiences an increase greather than $315 \mathrm{~V}$ or specified set point. This sharing mode operation will be used to stabilize the voltage on the DC Bus around the set point to supply the load demand on DC Bus. In this state, it is defined as an overload on DC Bus. The FB-BDC standby mode is activated when the voltage on DC Bus is in stable condition at appropriate voltage rating, in other terms the standby mode activated after both condition charging or sharing mode. Where, in this situation is defined as the state of voltage on DC Bus work normaly according to the set point. 




Figure 9. Design of reference value for mode activation of charging, sharing and standby

To be able to control operation mode of FB-BDC for charging, sharing and standby, a block diagram of control algorithm is shown in Figure 10. The system used voltage sonsor for sensing DC Bus voltage and Battery volatge, this measurement value of DC bus voltage used as feedback of controller. In the charging mode, the measurement value of DC bus voltage compared to the set point value, if the measurement value of DC Bus is higher than setpoint value the charging mode will be actived and the converter will charge the battery according to the predetermined set point of batttery voltage. in the sharing mode activated when the voltage on the DC Bus below the set point value. In this mode, the converter will stabilize the voltage on the DC bus according to the predetermined set point of DC Bus voltage.

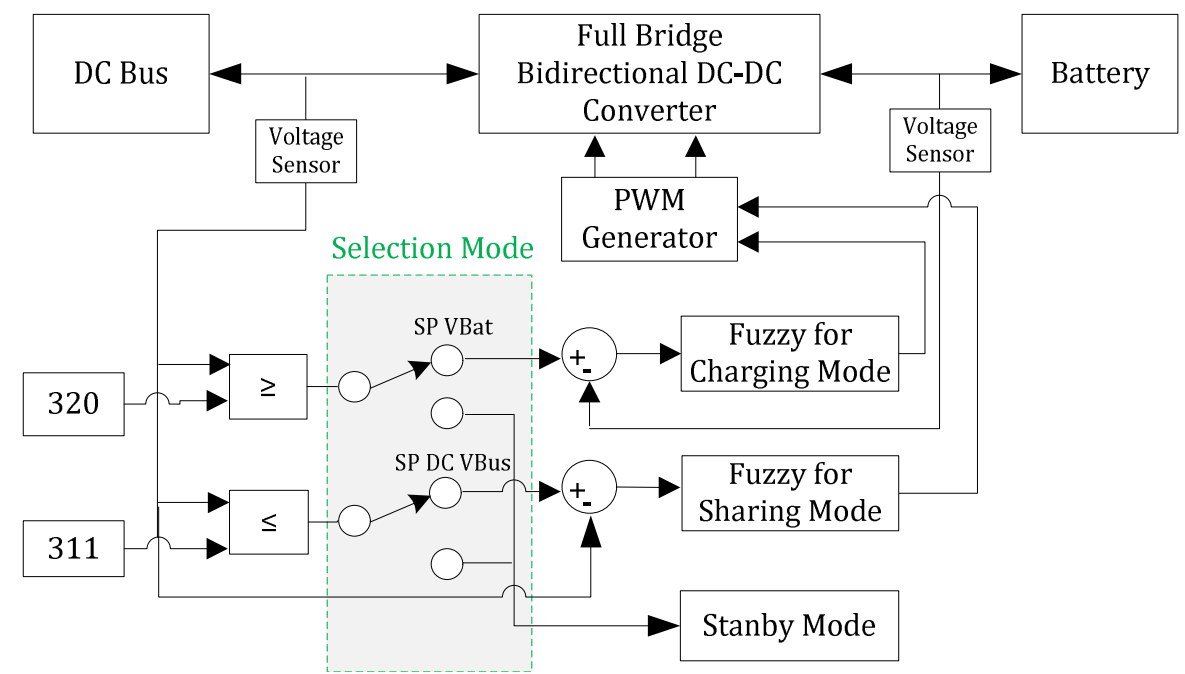

Figure 10. Proposed control algorithm for mode activation of charging, sharing and standby. 
In the proposed algorithm to operate mode of charging, sharing and stanby used selection by automatic switch, this activated by comparing DC Bus voltage and reference value. And then used separately fuzzy logic controller for charging and sharing, becasue the value of voltage is different bettwen DC Bus and Battery. In the stanby mode, FB-BDC is stop working just standby to work for sharing or charging. The design of membership function of error and delta error for charging mode operation described on Figure 11 and Figure 12, then the inference rule base to for charging mode on Table 2, and the defuzzyfication membership function on Figure 13.



Figure 11. The membership function of input error in charging mode

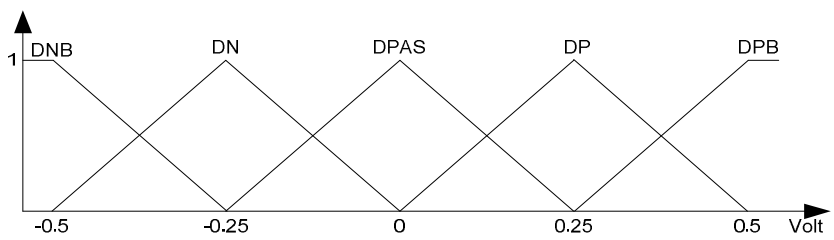

Figure 12. The membership function of input delta error in charging mode.

The rule base of the fuzzy logic inference system for evaluation used in the charging mode operation is a $5 \times 5$ combination rule of the input error and input delta error. Details of the inference rule base can be seen in Table 1.

Table 1. The inference rule base in charging mode operation

\begin{tabular}{|c|c|c|c|c|c|c|}
\multicolumn{2}{|c|}{} & \multicolumn{5}{|c|}{ Error } \\
\cline { 3 - 7 } & NB & N & Z & PS & PB \\
\hline \multirow{2}{*}{} & DNB & $\mathrm{kbs}$ & $\mathrm{kb}$ & $\mathrm{k}$ & $\mathrm{tb}$ & $\mathrm{kb}$ \\
\cline { 2 - 7 } & $\mathbf{D N}$ & $\mathrm{kbs}$ & $\mathrm{kb}$ & $\mathrm{k}$ & $\mathrm{tb}$ & $\mathrm{tbs}$ \\
\cline { 2 - 7 } & $\mathbf{D P A S}$ & $\mathrm{kbs}$ & $\mathrm{k}$ & $\mathrm{bs}$ & $\mathrm{t}$ & $\mathrm{tbs}$ \\
\cline { 2 - 7 } & $\mathbf{D P}$ & $\mathrm{kb}$ & $\mathrm{k}$ & $\mathrm{k}$ & $\mathrm{tb}$ & $\mathrm{tb}$ \\
\cline { 2 - 6 } & $\mathbf{D P B}$ & $\mathrm{kb}$ & $\mathrm{kb}$ & $\mathrm{k}$ & $\mathrm{tb}$ & $\mathrm{tbs}$ \\
\hline
\end{tabular}

The defuzzification output process in charging mode operation uses of the sugeno method fuzzy logic control is in the form of singleton. Where defuzzyfication with singleton is described as Figure 13. 


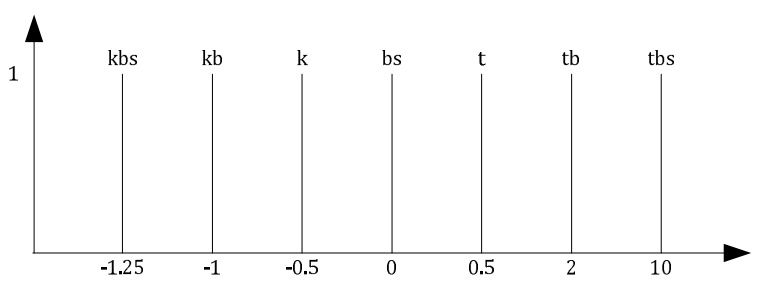

Figure 13. The membership function of defuzzification in charging mode.

The design of membership function of error and delta error for sharing mode operation described on Figure 14 and Figure 15, then the inference rule base to for charging mode on Table 3 , and the defuzzyfication membership function on Figure 16.

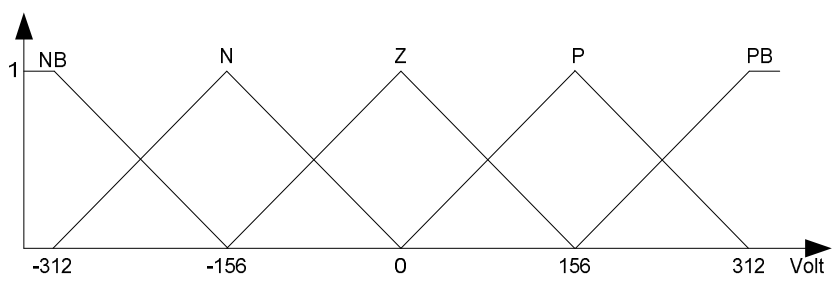

Figure 14. The membership function of input error in sharing mode

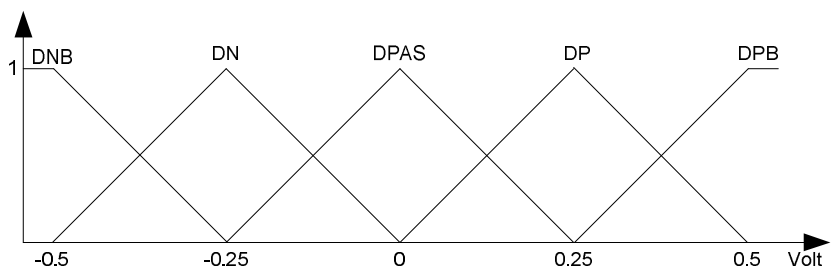

Figure 15. The membership function of input delta error in sharing mode.

The rule base of the fuzzy logic inference system for evaluation used in the sharing mode operation is a $5 \times 5$ combination rule of the input error and input delta error. Details of the inference rule base can be seen in Table 2.

Table 2. The inference rule base in sharing mode operation

\begin{tabular}{|c|c|c|c|c|c|c|}
\hline \multicolumn{2}{|c|}{} & \multicolumn{5}{|c|}{ Error } \\
\cline { 2 - 7 } & NB & N & Z & PS & PB \\
\hline \multirow{2}{*}{} & DNB & $\mathrm{kbs}$ & $\mathrm{kb}$ & $\mathrm{k}$ & $\mathrm{tb}$ & $\mathrm{kb}$ \\
\cline { 2 - 7 } & $\mathbf{D N}$ & $\mathrm{kbs}$ & $\mathrm{kb}$ & $\mathrm{k}$ & $\mathrm{tb}$ & $\mathrm{tbs}$ \\
\cline { 2 - 7 } & $\mathbf{D P A S}$ & $\mathrm{kbs}$ & $\mathrm{k}$ & $\mathrm{bs}$ & $\mathrm{t}$ & $\mathrm{tbs}$ \\
\cline { 2 - 7 } & $\mathbf{D P}$ & $\mathrm{kb}$ & $\mathrm{k}$ & $\mathrm{k}$ & $\mathrm{tb}$ & $\mathrm{tb}$ \\
\cline { 2 - 7 } & DPB & $\mathrm{kb}$ & $\mathrm{kb}$ & $\mathrm{k}$ & $\mathrm{tb}$ & $\mathrm{tbs}$ \\
\hline
\end{tabular}

The defuzzification output process in sharing mode operation uses of the sugeno method fuzzy logic control is in the form of singleton. Where defuzzyfication with singleton is described as Figure 16. 


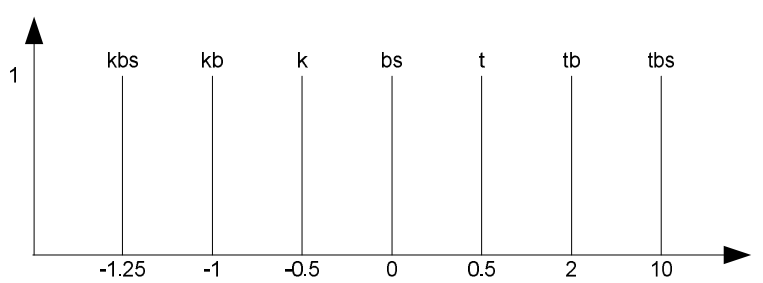

Figure 16. The membership function of defuzzification in sharing mode.

Table 3. The FB-BDC Parameter

\begin{tabular}{|l|c|c|c|}
\hline \multicolumn{1}{|c|}{ Parameter } & Name (Unit) & Sharing Mode & Charging Mode \\
\hline Minimum Battery Voltage & $\mathrm{Vs}_{\min }(\mathrm{V})$ & 72 & 340 \\
\hline Maximum Battery Voltage & $\mathrm{Vs}_{\max }(\mathrm{V})$ & 78 & 320 \\
\hline Output Voltage for DC Bus & $\mathrm{Vo}(\mathrm{V})$ & 311 & 82.3 \\
\hline Output Current for DC Bus & $\mathrm{Io}(\mathrm{A})$ & 1.56 & 3.6 \\
\hline Switching Frequency & $\mathrm{F}(\mathrm{KHz})$ & 20 & 20 \\
\hline Initial Duty Cycle & $\mathrm{D}(\%)$ & 75 & 27 \\
\hline Transformer Ratio & - & \multicolumn{2}{|c|}{$\mathrm{N} 1 / \mathrm{N} 2=184 / 84$} \\
\hline Inductor Low Voltage & $\mathrm{L} 1(\mathrm{uH})$ & \multicolumn{2}{|c|}{100} \\
\hline Capacitor Low Voltage & $\mathrm{C} 1(\mathrm{uF})$ & \multicolumn{2}{|c|}{100} \\
\hline Capacitor High Voltage & $\mathrm{C} 2(\mathrm{uF})$ & \multicolumn{3}{|c|}{} \\
\hline
\end{tabular}

To perform a good performance DC-DC converter, it is necessary to calculate every component value in the right value. If the value of the component used is incorrect, it can cause high ripple voltage and current. The parameters of the FB-BDC used in this paper described in Table 3. FB-BDC has output voltage for DC Bus of $311 \mathrm{~V}$ for sharing mode and 82.3 for charing mode. Output voltage of FB-BDC adjusted with grid and battery voltages. Moreover, output current for DC Bus of 1,56 A for sharing mode and 3,6 A for charing mode. Specification of switching frequency determined of $20 \mathrm{kHz}$ to decrease ripple of output voltage.

\section{EXPERIMENT AND ANALYSIS}

The experimental hardware prototype of FB-BDC can be seen in Figure 17 , at the bottom is the DC-DC converter power section, the second layer for signal conditioning board and the top is controller which is included the TFT LCD interface to display the voltage and current. 


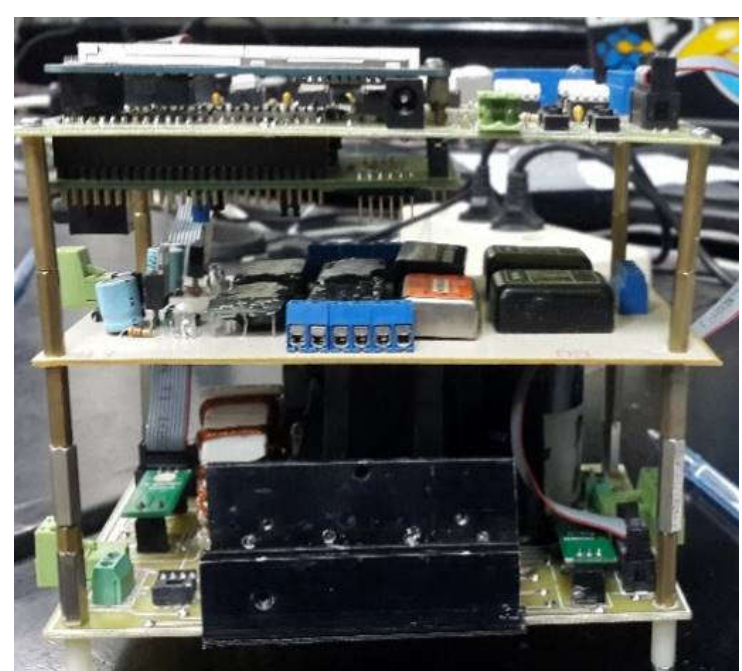

Figure 17. The experimental hardware prototype of FB-BDC.

\subsection{Result of charging mode.}

In the charging experiment FB-BDC works in charging mode. Where, FB-BDC input comes from DC Bus $320 \mathrm{~V}-340 \mathrm{~V}$, then the voltage is converted step-down to $82 \mathrm{~V}$ for charging $72 \mathrm{~V}$ battery. This charging mode start when the voltage on the DC Bus is greather than $320 \mathrm{~V}$, charging mode stop when the voltage on the DC Bus get down under $315 \mathrm{~V}$. The battery charging method used is a constant voltage type that is controlled using a fuzzy logic controller. To be able to control battery charging with constant voltage need a voltage sensor placed on battery therminal, the sensor used as feedback of fuzzy logic controller. The set point of charging voltage is formulated in equation 3 below.

set point of charging $=82$ - sensor reading of battery therminal

Where, 82 is the nominal voltage used for charging. In this experiment FB-BDC work very well to step-down the voltage from 335 Volts DC to 82 Volts DC with the current obtained at 2.6 A. The output voltage waveform observed by digital oscilloscope can be seen in Figure 18 and output current waveform in Figure 19. 


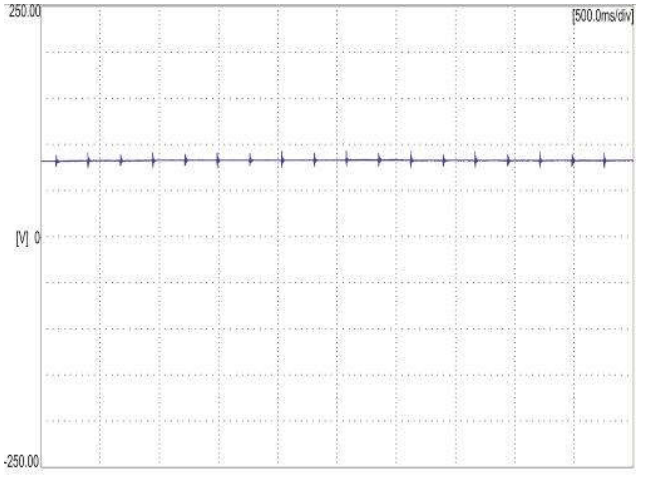

(a)

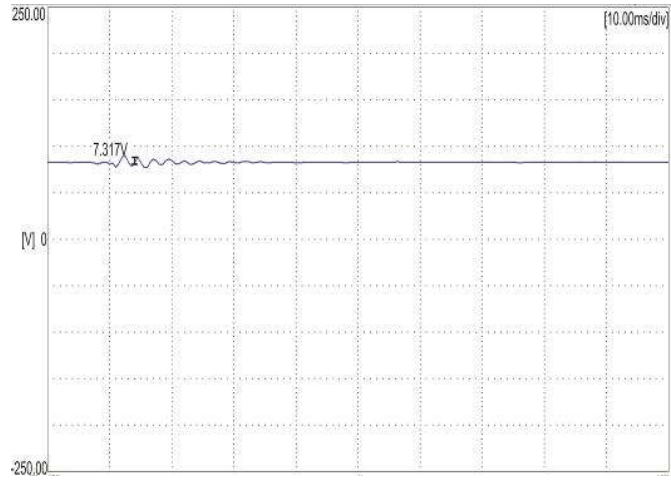

(b)

Figure 18. The FB-BDC output voltage to battery for charging mode, a. voltage waveform. b. Riplle Volatge.



(a)

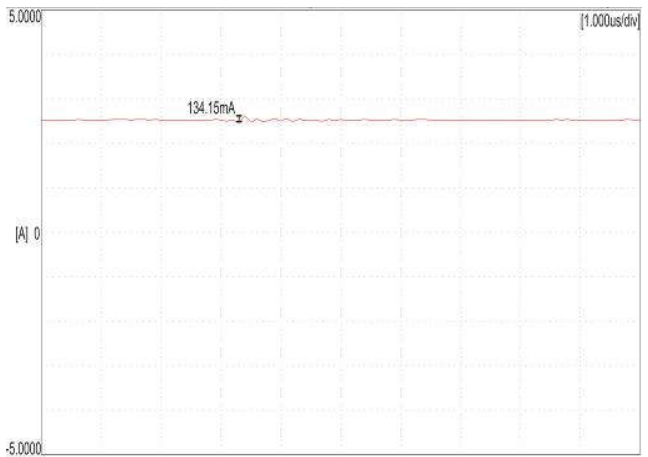

(b)

Figure 19. The FB-BDC output current to battery on charging mode, a. Current waveform. b. Riplle current.

In the experiment on charging mode operation, the fuzzy logic controller responses time on charging mode operation to achieve steady state requires 3.7 seconds. This response can be seen in Figure 20.

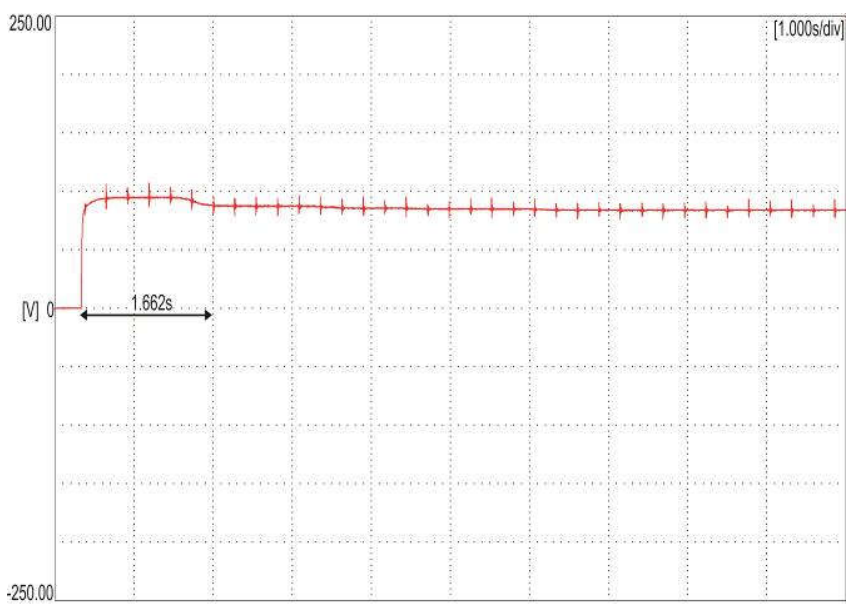

Figure 20. The FB-BDC output response time achieve steady state on charging mode operation. 
The FB-BDC also be tested with disturbance, Disturbance simulated with increasing and reducing DC Bus voltage in input full-bridge bidirectional DC-DC Converter. Disturbance is applied by DC power supply. The ability of Fuzzy logic controller to maintain charging voltage shown in Figure 21. On increasing DC Bus voltage FB-BDC need 2.88 second to achieve steady condition and on reducing DC Bus voltage FB-BDC need 2.11 second to achieve steady condition.

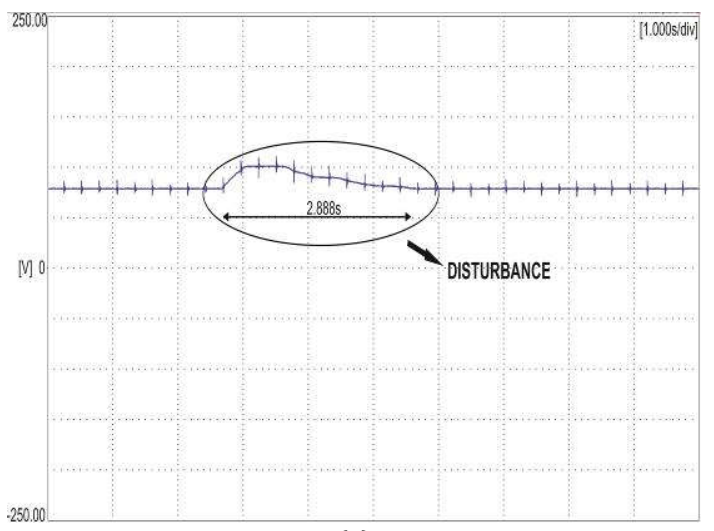

(a)

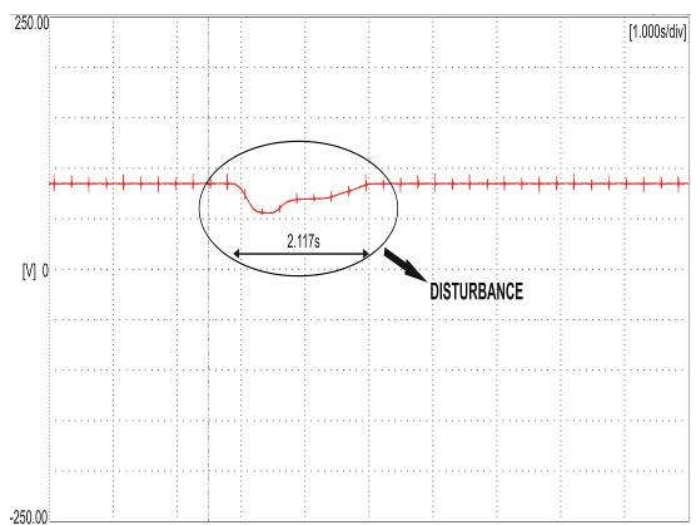

(b)

Figure 21. The FB-BDC output response time achieve steady state. a. On increasing DC Bus voltage, b. On reducing DC Bus voltage

\subsection{Result of sharing mode.}

In the sharing mode experiment FB-BDC works in sharing mode. Where FB-BDC input comes from battery $72 \mathrm{~V}$, then the voltage is converted step-up to $311 \mathrm{~V}$ DC Bus volatge. This sharing mode start when the voltage on the DC Bus is lees than $311 \mathrm{~V}$ and sharing mode will stop when the voltage on the DC Bus reach greather than $315 \mathrm{~V}$. In the sharing mode also used a constant voltage type that is controlled using a fuzzy logic controller. To be able to control DC Bus volatge with constan voltage need a voltage sensor placed on DC Buss, the sensor used as feedback of fuzzy logic controller. The set point of sharing volatge is formulated in equation 4 below.

set point of sharing $=311-$ sensor reading of DC Bus $(4)$

Where, 311 is the nominal voltage used on DC Bus. In this experiment FB-BDC work properly to step-up the voltage from 72 Volts DC to $310.5 \mathrm{~V}$ with the current obtained at $1.63 \mathrm{~A}$. The output voltage waveform on DC Bus can be seen in Figure 22 and output current waveform in Figure 23. 


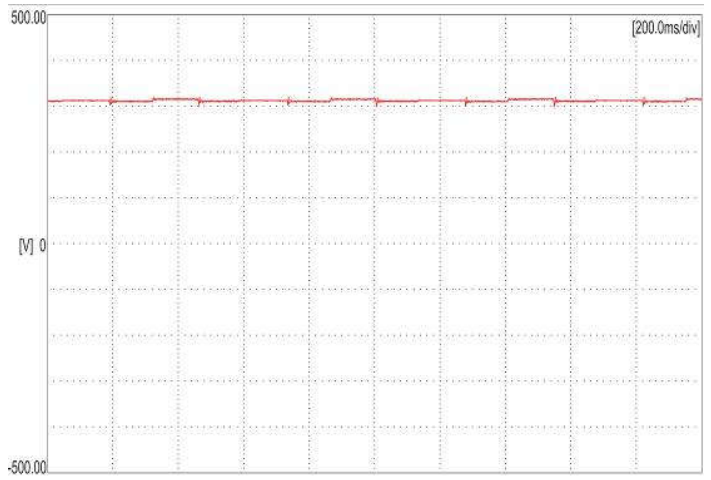

(a)

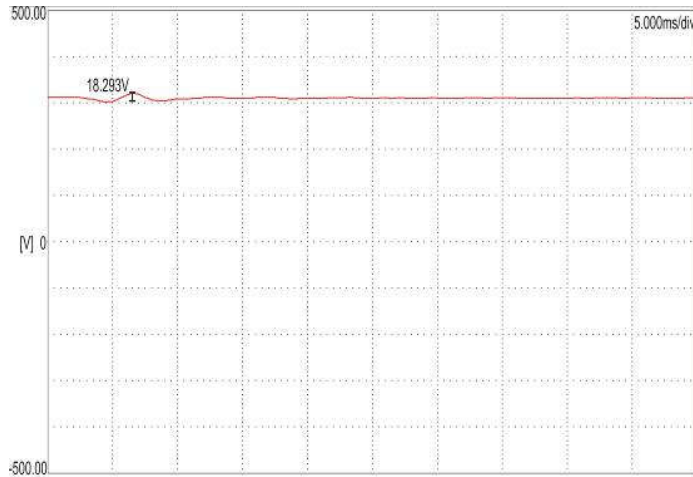

(b)

Figure 22. The FB-BDC output voltage to the DC Bus for sharing mode, a. voltage waveform. b. Riplle Volatge.

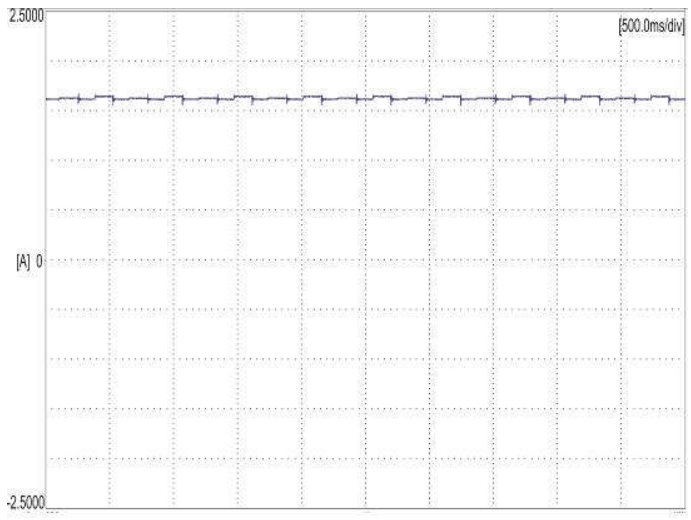

(a)

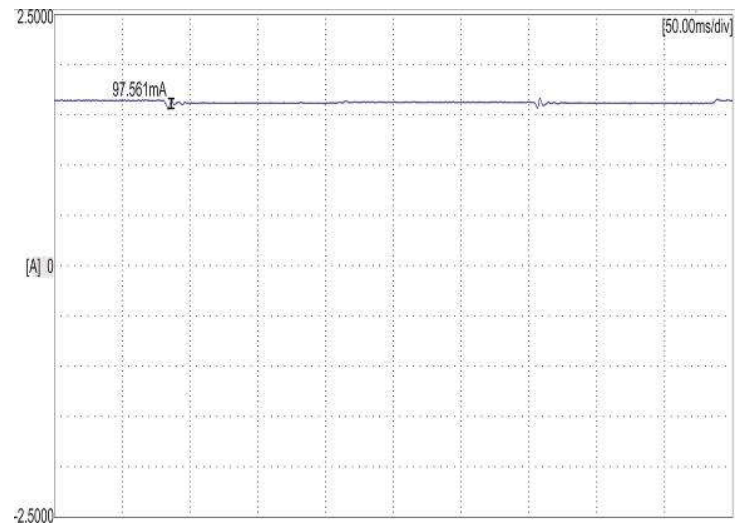

(b)

Figure 23. The FB-BDC output current to the DC Bus on sharing mode, a. Current waveform. b. Riplle current.

In the experiment on sharing mode operation, the fuzzy logic controller response time on sharing mode operation to achieve steady state requires 3.2 seconds. This response can be seen in Figure 24.

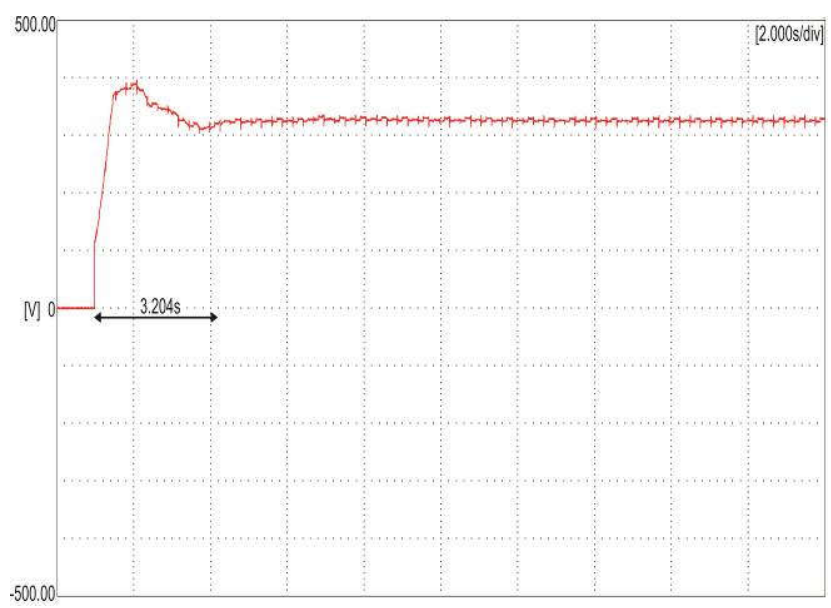

Figure 24. The FB-BDC output response time achieve steady state on sharing mode operation. 
The FB-BDC also tested with disturbance, Disturbance simulated with increasing and reducing DC Bus voltage in input full-bridge bidirectional DC-DC Converter. Disturbance is applied by DC power supply.. The ability of Fuzzy logic controller to maintain charging voltage shown in Figure 25. On increasing DC Bus voltage FB-BDC need 4.20 second to achieve steady condition and on reducing DC Bus voltage FB-BDC need 4.28 second to achieve steady condition.

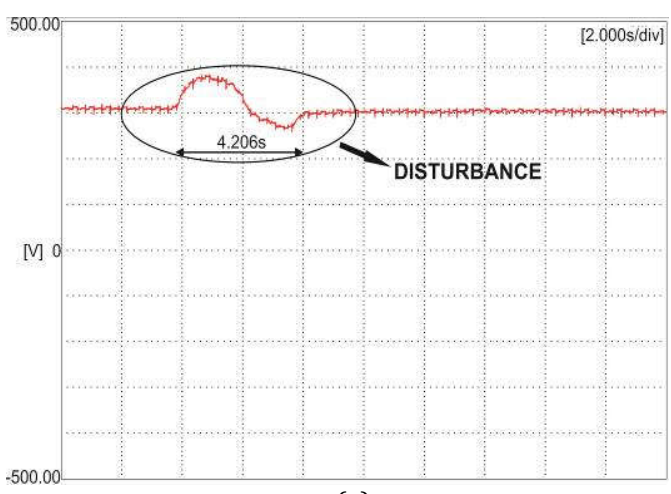

(a)

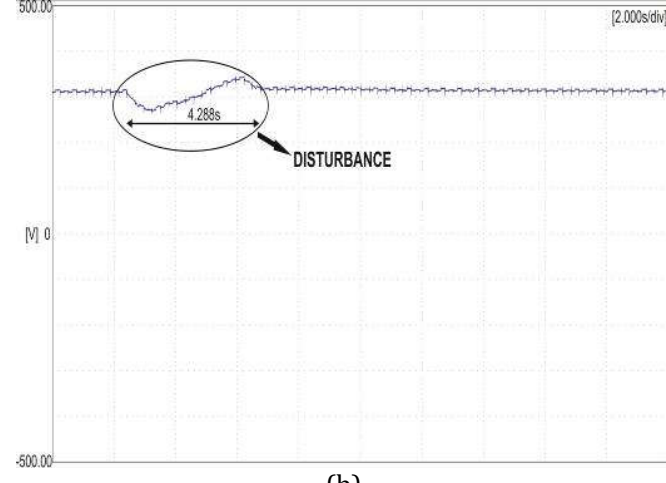

(b)

Figure 25. The FB-BDC output response time achieve steady state. a. On increasing DC Bus voltage, b. On reducing DC Bus voltage

\section{CONCLUSION}

The experiment results show that FB-BDC with Fuzzy Logic Controller worked properly perform bidirectional energy transfer both charging mode and sharing mode and also regulated the DC-Bus voltage according to referenced value. In charging mode, has succeeded in step-down the voltage from 320 Volts to 82 Volts for charging the battery with an error percentage of less than $1 \%$. In sharing mode, it has managed to step-up the voltage from 72 volts to 311 Volts. With an error percentage of less than $1.5 \%$. Fuzzy control response to reach steady state in charging mode takes 3.7 seconds while in fuzzy response sharing mode it takes 3.2 seconds to reach steady. From this reason can be concluded that FB-BDC succeessfull controled with Fuzzy Logic Controlle for regulate voltage both for charging and sharing mode on energy storage application.

\section{REFERENCES}

[1] Trowler, Derik. Whitaker, Bret. Bi-Directional Inverter and Energy Storage System. Texas Instruments Analog Design Contest. May 2008.

[2] Kusdiana, Dadan., Real conditions of energy in Indonesia and renewable alternative energy sources, Directorate General of Energy and Energy and Mineral Resources Utilization, Bogor, 3 December 2008.

[3] Saleh, Darwin Zahedy., The electricity development master plan for 2010 to 2014, Ministry of Energy and Mineral Resources of the Republic of Indonesia. Jakarta, December 2009. 
[4] S. Inoue and H. Akagi. A bidirectional isolated dc/dc converter as a core circuit of the next generation medium voltagepower conversion system, IEEE Trans. Power Electron. 22(2), 535-542 (2007).

[5] Kuei-Hsiang Chao, Ming-Chang Tseng, Chun-Hao Huang, Yang-Guang Liu, and Liang-Chiao Huang, Design and Implementation of a Bidirectional DC-DC Converter for Stand-Alone Photovoltaic Systems, International Journal of Computer, Consumer and Control (IJ3C), Vol. 2, No.3, 2013.

[6] Alireza Bakhshai. Bidirectional DC - DC Converters for Energy Storage Systems, Energy Storage in the Emerging Era of SmartGrids, Prof. Rosario Carbone (Ed.), ISBN: 978-953-307-269-2, InTech, September 2011.

[7] Nadia Mei Lin Tan, Takahiro Abe, Hirofumi Akagi, Design and Performance of a Bidirectional Isolated DC-DC Converter for a Battrey Energy Storage system, IEEE Transactions on Power Electronic vol.27 No3, March 2012.

[8] N. Mohan, T.M. Undeland, W.P. Robbins, Power Electronics: Converters, Applications, and Design, $2^{\text {nd }}$ ed., 1995, Wiley, New York, USA.

[9] D. W. Hart, Introduction to power electronics, Prentice, Prentice-Hall of USA, New York, 2003.

[10] D.Xu, C. Zhao, and H. Fan. A PWM Plus Phase- Shift Control Bidirectional DC-DC Converter, IEEE Trans. Power Electron., Vol.19, pp.666-675, May 2014

[11] Mofakkharul Islam, Masuma Masrin, Abu Bashar Sarkar, An Isolated Bidirectional DC-DC Converter for Enenrgy Storage System, PCIM Europe, May, Nuremberg Germany, 2017.

[12] Rugaju, M. Janse van Rensburg, J.F dan Pienar H.C.vZ, Full Bridge DCDC Converter as Input Stage for Fuel Cell Inverter System,Vaal University of Technologi,1900.

[13] Dehnavi, sayed M.D, Gokhan, Thomsen Ole Cornelius, Andersen Michael, Moller Lars, Isolated Bidirectional DC-DC Converter for SuperCapasitor Application, ICREPQ'11 International Conference on Renewable Energies and Powe Quality, Technical Universty of Denmark, 2011.

[14] Muhammed Shaveel T M, Vinod John, Isolated Bidirectional DC-DC Power Supply for Charging and Discharging Battery, Indian Institue of Science, Bangalore India, 2013.

[15] Ganji Sai Kumar, G. Ramudu, D. Vijay Arun, Analysis and Implementation of bidirectional DC to DC Converter by using Fuzzy logic Controller, The International Journal of Engineering and Science (IJES), Volume 3, Issue 6, Pages 22-39, 2014.

[16] A. Srilatha, Fatimaazraand R. Venkatezwarlu, Fuzzy logic controlled bidirectional dc-dc converter applied to dc drive, International 
Journal of Electrical and Electronics Engineering Research (IJEEER), Vol. 4, Issue 6, 25-36. Dec 2014.

[17] A. Uma Siva Jyothi, D S Phani Gopal and G. Ramu, Bi-Directional Dc-Dc converter Drive with PI and Fuzzy Logic Controller, International Journal of Advanced Research in Electrical, Electronics and Instrumentation Engineering, Vol. 2, Issue 11, November 2013.

[18] Prasetyono, E., Anggriawan, D.O., Firmansyah, A.Z., Windarko, N.A., "A modified MPPT Algorithm Using Incremental Conductance for Constant Power Generation of Photovoltaic Systems", International Electronics Symposium on Engineering Technology and Application, 2017

[19] Wahjono, E., Anggriawan, D.O., Sunarno, E., Nugraha, S. D., Tjahjono, A., "Maximum Power Point Tracking of Photovoltaic Module for Battery Charging Based on Modified Particle Swarm Optimization", International Review on Modelling and Simulations, Vol. 10, No. 1, 2017

[20] Tjahjono, A., Qudsi, O.A., Windarko, N.A., Anggriawan, D.O., Priyadi, A., Purnomo, M.H., "Photovoltaic Module and Maximum Power Point Tracking Modelling Using Adaptive Neuro-Fuzzy Inference System", IEEE conference of Makassar International Conference on Electrical Engineering and Informatics (MICEEI), Nov., 2014

[21] Deepika M, Marimuthu M, Paranthagan B. Comparative analysis of proportional integral derivative controller and Fuzzy Logic controller on interleaved soft switching boost converter. International Conference on Circuit, Power and Computing Technologies (IEEE) 2014:307-312. 